\title{
THE EFFECTS OF SUSTAINED PITUITARY ANTIDIURESIS AND FORCED WATER DRINKING IN EPILEPTIC CHILDREN. A DIAGNOSTIC AND ETIOLOGIC STUDY 1,2
}

\author{
By IRVINE MCQUARRIE AND D. B. PEELER
}

(From the Departments of Pediatrics of the University of Rochester, Rochester, N. Y., and the University of Minnesota, Minneapolis)

(Received for publication June 29, 1931)

In the course of work already reported (1) (2) on the relationship of water balance to the occurrence of convulsions in severely epileptic children, it was found that seizures, after having been brought under control by the production of a deficit in the body water, could be made to recur practically at will by the rapid reestablishment of a positive water balance with pituitary antidiuresis. The investigation reported in the present paper was undertaken with the purpose of further elucidating the mechanism of this reaction, which appeared to us to open a new avenue of approach to the complex problem of etiology in epilepsy.

In order to avoid misinterpretations based upon the spontaneous occurrence of seizures, patients were selected who were known to have convulsions infrequently but with a fair degree of regularity. It was believed that any fundamental difference that might be found between the response of the normal subject to an artificially induced disturbance in the body fluid relationships and that of the epileptic patient during his usual period of freedom from seizures, might furnish valuable information regarding the underlying physicochemical pathology in epilepsy. The possibility of utilizing the observed reaction of the severe epileptic to an enforced positive water balance as a diagnostic procedure in mild or obscure cases also occurred to us early in the study. Other means by which seizures can often be provoked in severe epi-

${ }^{1}$ Presented at the Twenty-third Annual Meeting of the American Society for Clinical Investigation, Atlantic City, May 4, 1931.

${ }^{2}$ Aided by grants from an anonymous donor and from the Fluid Research Fund of the Rockefeller Foundation. 
lepsy, such as hyperventillation of the lungs (3) and the production of marked alkalosis from ingestion of sodium bicarbonate (4), are rarely effective in the mild cases during the intervals between their infrequent seizures. This observation led McQuarrie and Keith (5) to conclude that the mildly epileptic patient is indistinguishable from the normal child during his free periods. It will be seen, however, that the results presented here necessitate a reversal of that opinion.

\section{PLAN OF INVESTIGATION}

The experimental subjects consisted of three groups of children. The first was made up of patients who gave personal histories more or less typical of "idiopathic" epilepsy, but had seizures at infrequent intervals. The second included cases with very indefinite histories of "fainting spells" or "sleepy spells" but no history of generalized convulsions or true petit mal. The third group consisted of essentially normal children admitted to the Hospital for study of behavior problems arising from social maladjustment at home or in school. Two cases of hysteria were also included. Pertinent details regarding the histories and results of other examinations are briefly summarized in connection with the presentation of the experimental data. The general neurological examinations, spinal fluid findings and $x$-ray plates of the skull were essentially normal and the Wassermann and tuberculin tests were negative in all of the cases presented here. Encephalographic studies after replacement of the cerebrospinal fluid by air (Dandy 6) were not included in this series of cases. However, a fairly large number of encephalograms were made subsequently in similar cases according to the modified technique outlined by Pancoast and Fay (7) and by Pendergrass (8). These have contributed little to our study since the pictures in the mildly epileptic children were practically indistinguishable from those of the non-epileptic subjects. The amount of removable cerebrospinal fluid was likewise essentially the same in the two groups.

The spinal fluid pressure was determined regularly after the first seizure in the epileptic patients and at the height of the reaction in six of the non-epileptic subjects studied. With the child lying quietly in the horizontal position on one side with the head slightly extended, water manometer readings were made before any fluid had been re- 
moved. Readings were obtained between two seizures in several cases.

All patients were kept in bed under close observation, either in the special metabolism ward, where complete study of the water and mineral balances could be conducted, or on the regular pediatric divisions of the Hospitals at the University of Rochester or at the University of Minnesota. The mixed diet ordinarily used on the pediatric services was given at first, but later this was replaced by diets comparatively low in $\mathrm{NaCl}$. Two of the epileptic patients were kept on basic diets, consisting exclusively of heavy cream, sugar and water, the purpose being to limit the mineral intake to an extremely low level, except for short periods when carefully weighed amounts of $\mathrm{NaCl}$ were added for a special purpose.

While under observation the patients were weighed regularly every 6 or 12 hours on scales sensitive to 5 grams. The bladder was emptied just before the patient was weighed. For each subject, the 24-hour diet as well as the water was divided into four equal amounts, which were given at 6 -hour intervals immediately after the patient had been weighed.

To produce a positive water balance, water was given at the rate of from 2 to 5 cc. per kilogram of body weight per hour at either 3- or 4-hour intervals simultaneously with a sufficient amount of the antidiuretic extract from the posterior lobe of the hypophysis (either pituitrin or pitressin P.D.) to prevent water diuresis. In the earlier experiments the extract was administered intranasally on a pledget of absorbent cotton, but the subcutaneous route was later adopted because it gave less variable results. The water and the extract were discontinued only when the patient had a seizure or manifested fairly marked symptoms of overdosage, such as abdominal cramps, excessive vomiting or slight headache. The body weight usually increased by 2 per cent or more before these symptoms appeared.

For the experiments presented in Charts 6 and 7, the patients were kept in the metabolism ward under the constant supervision of special nurses. The water intake per day was the same throughout the period of observation, and that for each day was divided into 8 equal portions given at 3-hour intervals simultaneously with the administration of pitressin. The diets, consisting of cane sugar and 40 per cent cream in non-ketogenic proportions, were calculated to meet the patients' 
energy requirements under ordinary conditions. Because of the shortness of the experimental period, it was thought unnecessary to give special attention to the protein or vitamin content of the diet. All food was given during the first two hours of each 6-hour period. The urine was collected quantitatively at the end of each period. The patient was weighed at the beginning of each 6-hour period, after the bladder had been completely emptied and before food or water had been given. The temperature and humidity of the room were such that visible sweating did not occur. The insensible water loss was calculated from the body weight changes.

"Water output," as shown in the balance charts, designates the water of the "insensible perspiration" plus that of the urine and feces. "Water intake" includes the drinking water, the preformed water of the food and the calculated water of oxidation. The $\mathrm{NaCl}$, which was given three and one-half days in the first, and four days in the second experiment, was taken in the drinking water in hypotonic concentration (about 0.4 per cent) at a uniform rate. We wish to emphasize the important fact that the salt was at no time given in hypertonic concentration. Full cooperation of the patient and his parents was secured for each study made.

\section{RESULTS}

For economy of space and for the sake of clearness, the results of representative experiments have been condensed on seven graphic charts, which are practically self-explanatory.

On Chart 1 are presented the data from studies on two patients giving histories typical of mild "essential " epilepsy, and on one non-epileptic control case in the same age period.

The control subject, V. M., was a comparatively healthy girl whose chief complaints were nervousness, enuresis and poor adjustment in school. Thorough examinations for evidence of urological, nervous, metabolic and circulatory disease were negative. She had never had signs of any convulsive disorder. D. M., the first patient, was an Italian boy in the same age and weight group who was referred from another hospital dispensary with the diagnosis of "genuine" epilepsy. He gave a definite history, dating back 3 years, of occasional severe grand mal seizures, which usually occurred in the early morning hours 

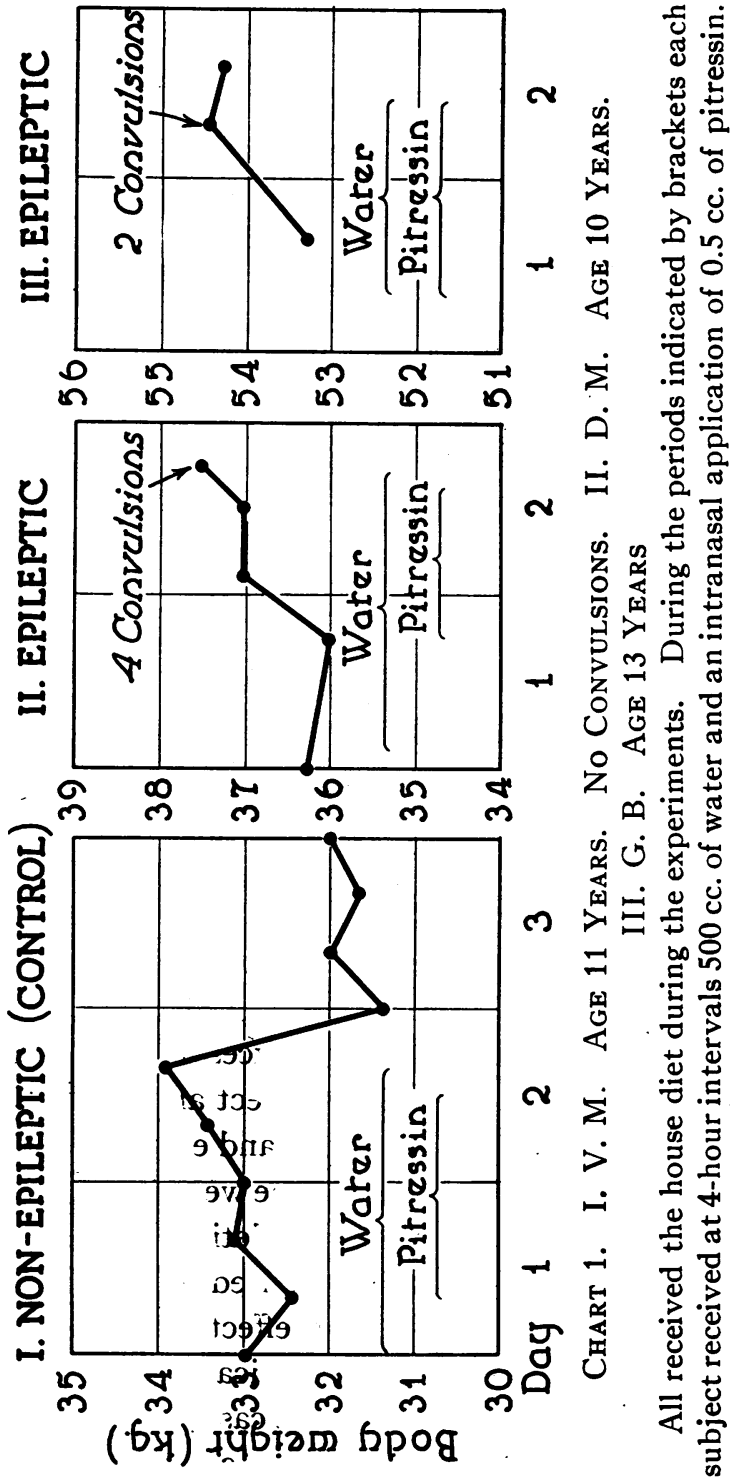
and were followed by stuporous sleep. The last attack had been two days prior to his admission to our Hospital. Except for dental caries, his general condition was found to be excellent. The second patient, G. B., a somewhat older and larger boy was brought to the Hospital for examination by members of a children's-aid society, who had obtained the history that there had been typical generalized epileptiform convulsions for three years, which had gradually become more frequent. During the previous year the seizures had occurred regularly every three or four weeks, the last having been three days before he entered the Hospital. Although there was slight mental subnormality, his general condition was essentially normal.

It is evident that the antidiuretic effect of the hypophyseal extract, which was administered intranasally, was of the same order in the nonepileptic as in the epileptic subjects. In fact, the percentage weight gain was slightly greater in the first case than in the two latter. Following the gain in weight, convulsions occurred in the epileptic patients as the first prominent effects of the test. An unusual feature of the reaction in the case of $D$. M. was that he had four convulsions in quick succession, whereas in no previous attack had he experienced more than one. That the control subject, in whom no convulsive phenomena were provoked, had a sufficient amount of water and extract for a fair test is shown not only by a large gain in weight but by the fact that headache and vomiting occurred as well.

The initial effect of increased water intake before the antidiuretic extract was given, namely, a loss in body weight, was the same in the normal subject as in the epileptic. The exyessive loss of weight which followed withdrawal of the antidiuretic effect gnd water in the control case is regularly observed in both normal and epileptic subjects. This will be discussed later. Unfortunately, the weights of the two epileptic patients were not recorded after the complation of their tests.

The experiments on Chart 2 are presented in part to illustrate the frequently observed variability of the efect on weight of pitressin, when it is administered by surface applicsation within the nostrils. When the water intake is high, as in these G̊s from time to time in spite of the antidiuretic,' thereby interfering with the object of the test. Subcutaneous administration has given more consistent results than intranasal in our experience. 


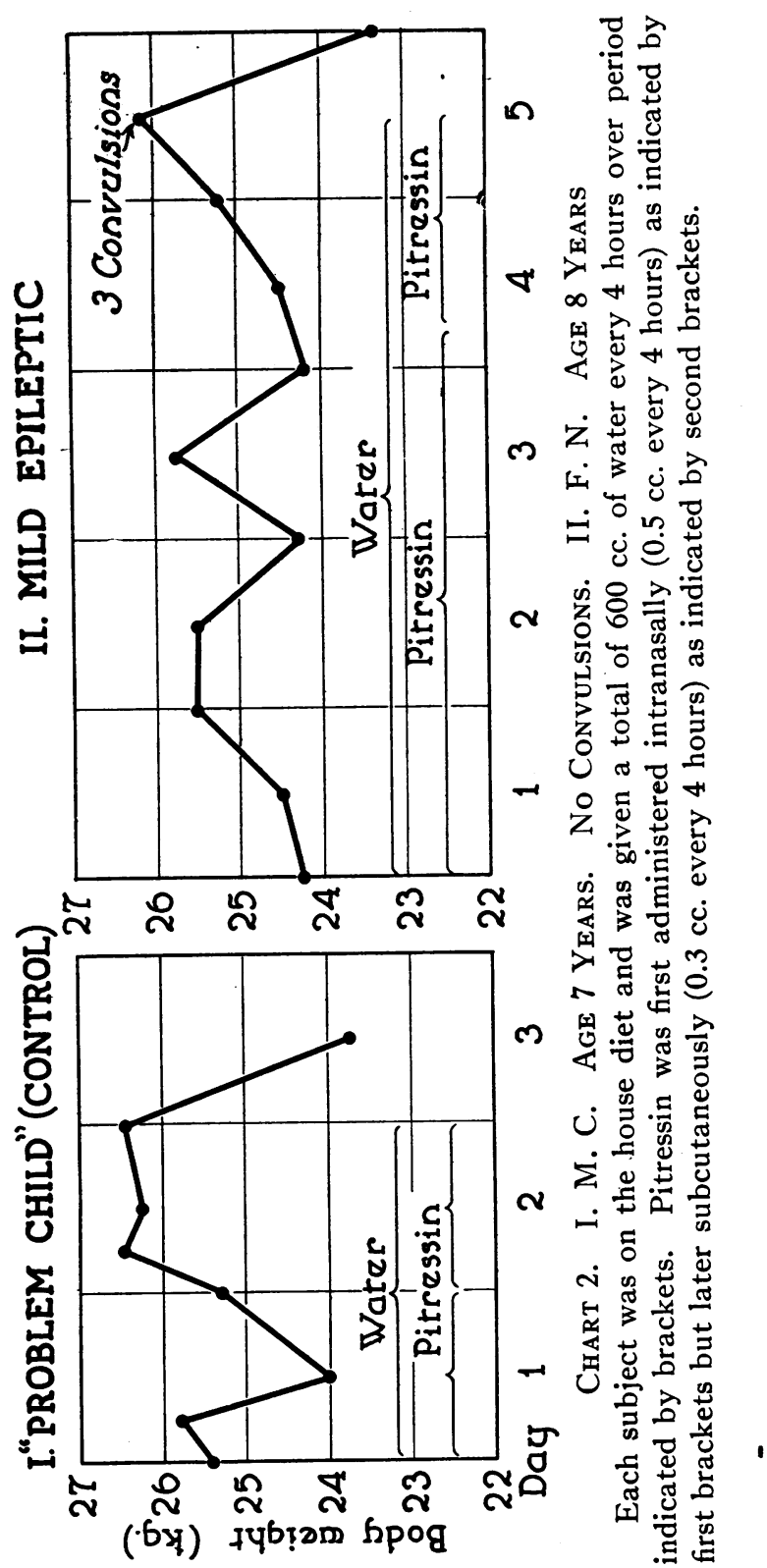


This chart again shows that the establishment of a positive water balance, indicated by the sudden gain in body weight, induced convulsions in the epileptic, but not in the non-epileptic subject. The maximum fluctuations in weight were approximately the same in both.

In connection with this particular experiment, the results on another patient receiving pitressin intranasally should be mentioned because of his unusual reaction. The subject was a boy 15 years of age, who gave a typical history of grand mal epilepsy since the age of 9 years with infrequently occurring seizures The test was performed as in the present experiment. The feature of special interest in this case was that after the storage of water had reached a level at which a seizure might have been expected, the patient experienced a definite aura without having a true seizure. Immediately after this reaction, diuresis developed and did not disappear so long as water was forced, in spite of continued intranasal application of the antidiuretic extract. We have not been able to explain this anomalous physiological reaction, although we have often seen polyuria follow a completed epileptic convulsion when no antidiuretic extract was being given.

Chart 3 presents data from tests on two patients, both with the tentative admission diagnosis of "epilepsy."

C. A. gave an indefinite history of "nervousness" and "fainting spells," which had occurred at infrequent intervals. She usually complained of "feeling faint" before swooning. She had at times sunk to the floor unconscious, but had never injured herself. This had happened when she was in an over-heated room and again when dancing. Frothing at the mouth, biting of the tongue, loss of sphincter control, violent muscular contractions or prolonged periods of drowsiness or sleep after attacks never occurred. She was somewhat retarded mentally, but appeared normal otherwise. It was the impression of Dr. Ferguson of the Neuropsychiatric department, who saw her in consultation before the test was made, that she was not a genuine epileptic.

E. B., on the other hand, gave a definite history of convulsions, the first of which had appeared at the age of 9 years. They had recurred biennially up to the age of 13 years, when her menstrual periods began. Since that time, she had had typical grand mal attacks every few months. Her mental development has remained essentially normal, however. 


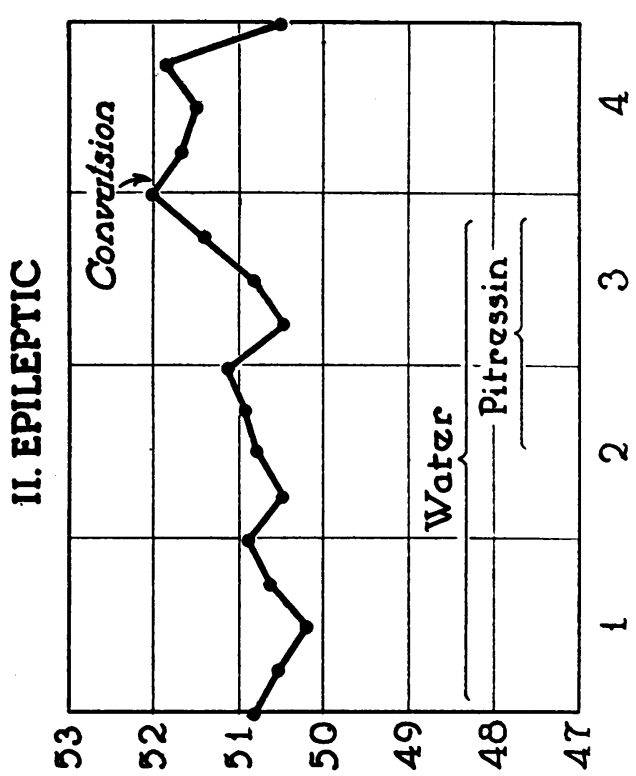

*

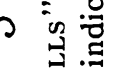

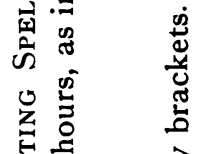

त 结

일

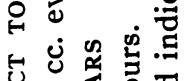

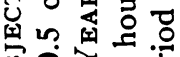
爷 0 in m

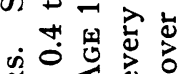

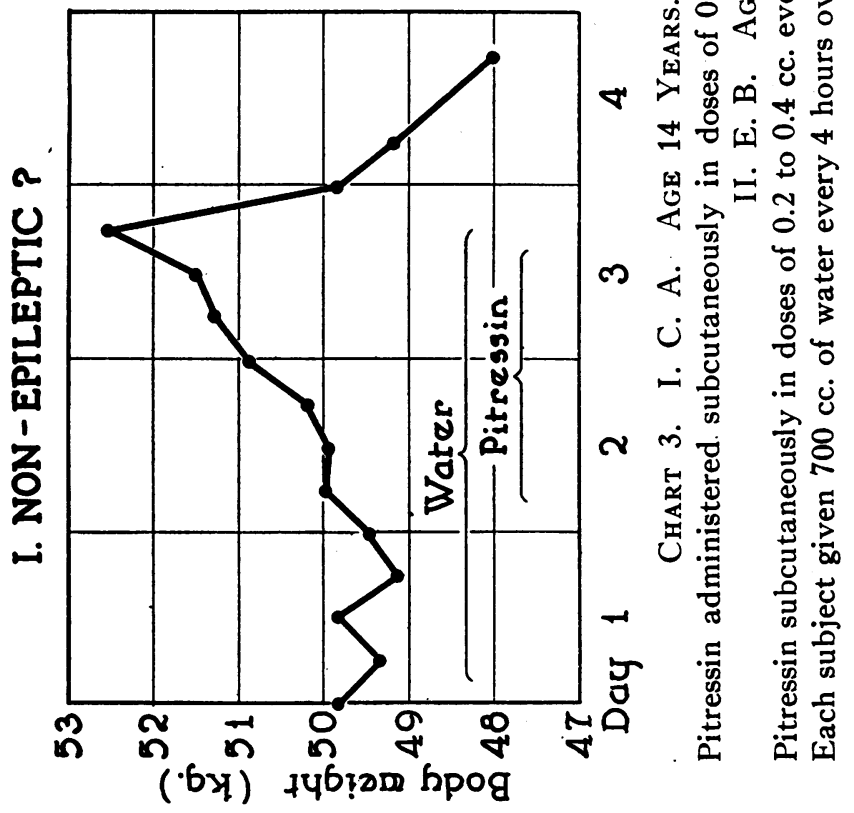


The difference in reaction of these two girls to the positive water balance test was very striking. The experimental conditions were essentially the same in both cases, except for the fact that E. B. was given somewhat smaller doses of pitressin. Although the conditions of the test were thus made much more extreme in the case of C. A., finally producing headache, vomiting and a fairly marked vasomotor response, she had no sign of fainting or of a convulsive seizure. On the other hand, E. B., with but half the gain in weight from water retention and with very little evidence of the other symptoms mentioned, had a typical grand mal attack preceded by a definite aura. Following withdrawal of the pitressin, E. B. showed delay in diuresis not seen in any other patient.

The three experiments presented on Chart 4 are of special interest because each of the patients involved exhibited a peculiar diagnostic problem requiring more information for its solution than that available from the ordinary neurological examination. Subsequent observation has confirmed the accuracy of the conclusions indicated by the tests.

M. J. B. gave a history suggestive of possible brain injury at birth, although at the time of our examination there were no neurological signs of residual organic disease and no evidences of mental retardation. The mother's labor was said to have been precipitous. The patient had one generalized convulsion during the first week of life and at that time red blood cells were found in the spinal fluid. The next convulsion occurred three years later. This was followed by hemiparesis which did not disappear entirely for several days. No seizures were seen thereafter for two years. At the end of this period, two weeks before admission to the Hospital, however, a third severe generalized convulsion occurred, which could not be explained on any other basis than that of epilepsy. There was a family history strongly suggestive of this disorder.

Before the performance of this special test was considered, we were requested to give an opinion regarding the cause of her convulsions. She had then been in the Hospital for over a week for careful neurological and psychiatric study, the results of which were essentially negative, and was about to be discharged with the diagnosis, "nervous child." We were reluctant to perform the test because of the history of paresis 


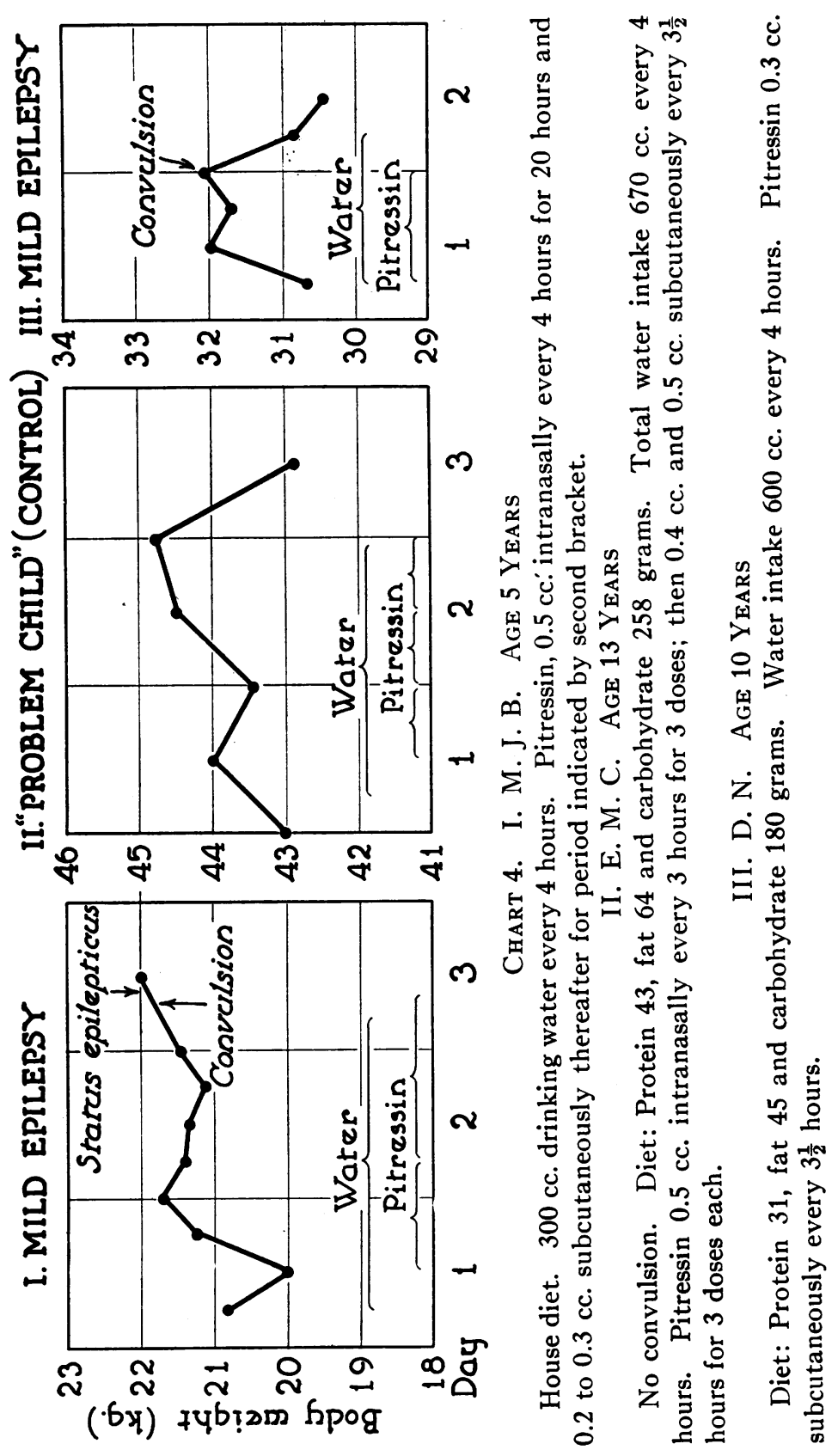


following one of her previous attacks. However, the parents and the family physician were willing to assume responsibility for possible ill effects from it because they were somewhat dissatisfied with the indefiniteness of the provisional diagnosis.

During the first 24 hours the test was without definite effect because of over-caution regarding the dosage of pitressin. When the latter was increased, however, seizures resulted within 18 hours. It is probable that an unobserved seizure occurred just before the last dose of the extract was given because the patient had otherwise unexplained enuresis and drowsiness. When the attacks began to appear with great frequency, they were brought under control by the induction of light chloroform anesthesia. No noticeable ill effects resulted. This particular experience, however, emphasizes the desirability of terminating the period of antidiuresis as soon as the first seizure has occurred. Since her discharge from the Hospital, the diagnosis of epilepsy has been further confirmed by recurrence of seizures on two occasions several months apart.

As shown in the second division of the chart, no convulsion was induced when the test was performed on a "behavior-problem" child, who gave a history of six or seven atypical "fainting spells" during the previous three years. In none of these had there been observed complete loss of consciousness, convulsive movements, frothing at the mouth, cyanosis or injury from falling. Members of the staff in Neuropsychiatry had never considered her to be an epileptic. Her "spells" were regarded as a feature of her behavior disorder. As shown on the chart, no seizures occurred in spite of a gain of two kilograms in body weight from water storage. Vomiting, abdominal discomfort and headache finally necessitated the termination of the test. That this patient served as a reliable control is confirmed by her subsequent history.

From the clinical point of view the patient, who served as subject for the experiment presented in the third division of Chart 4, was in several respects the most interesting studied. While she gave a long history of grand mal seizures in every respect typical of true epilepsy, neurological examination revealed the absence of a normal gag reflex and the presence of peripheral anesthesia with the "stocking and glove" distribution characteristic of hysteria. Further investigation of the history 
brought out the fact that during the previous two years, the patient had suffered from "nervousness," and transient attacks of dizziness, headache and precordial pains, with no physical findings to explain such symptoms. The latter appeared to have no relationship to the seizures, but had developed subsequently, during a period when the mother was suffering from severe exophthalmic goiter, which kept the family as well as herself under "high nervous tension." The child's symptoms, like the mother's, had greatly improved following removal of the mother's goiter. Until these features suggesting hysteria were discovered, the clinical diagnosis, based upon the character of the convulsive seizures, had been epilepsy.

When the antidiuresis test was performed, every precaution was taken to keep the patient from knowing its purpose or from knowing that she was being observed. That the convulsion which followed was not hysterical in character is practically certain. It occurred only after the patient's body weight had been increased over 4 per cent by retained water. As described by Dr. Clausen and members of his staff, who were making ward rounds in an adjoining room when called to see the patient, the convulsion was typical of the grand mal seizure of geniune epilepsy. A characteristic aura was reported by the supervising nurse. The pupils were widely dilated and the eyeballs were turned upward and to one side. There was a definite tonic phase with cyanosis and twisting of the body to one side, followed by a clonic phase with drooling and frothing at the mouth. There was no definite loss of sphincter control and the tongue was not bitten, but the seizure was followed by a long sleep.

The conclusion was drawn that the patient was a true epileptic, with superimposed hysteria of a mild grade, which had manifested itself in other ways than by means of convulsions.

The experiment presented in Chart 5 differed from those preceding in several ways. The patient was an intelligent, well developed, 16year-old Armenian girl who gave a typical history of so-called genuine epilepsy of one year's duration. Grand mal seizures had occurred monthly or bimonthly almost from the beginning. The time selected for the test, as in the previous cases, was within the period when no regular seizure was expected. A preliminary test, with the pitressin administered intranasally, was unsuccessful as regards the physiological response and the production of a seizure. 


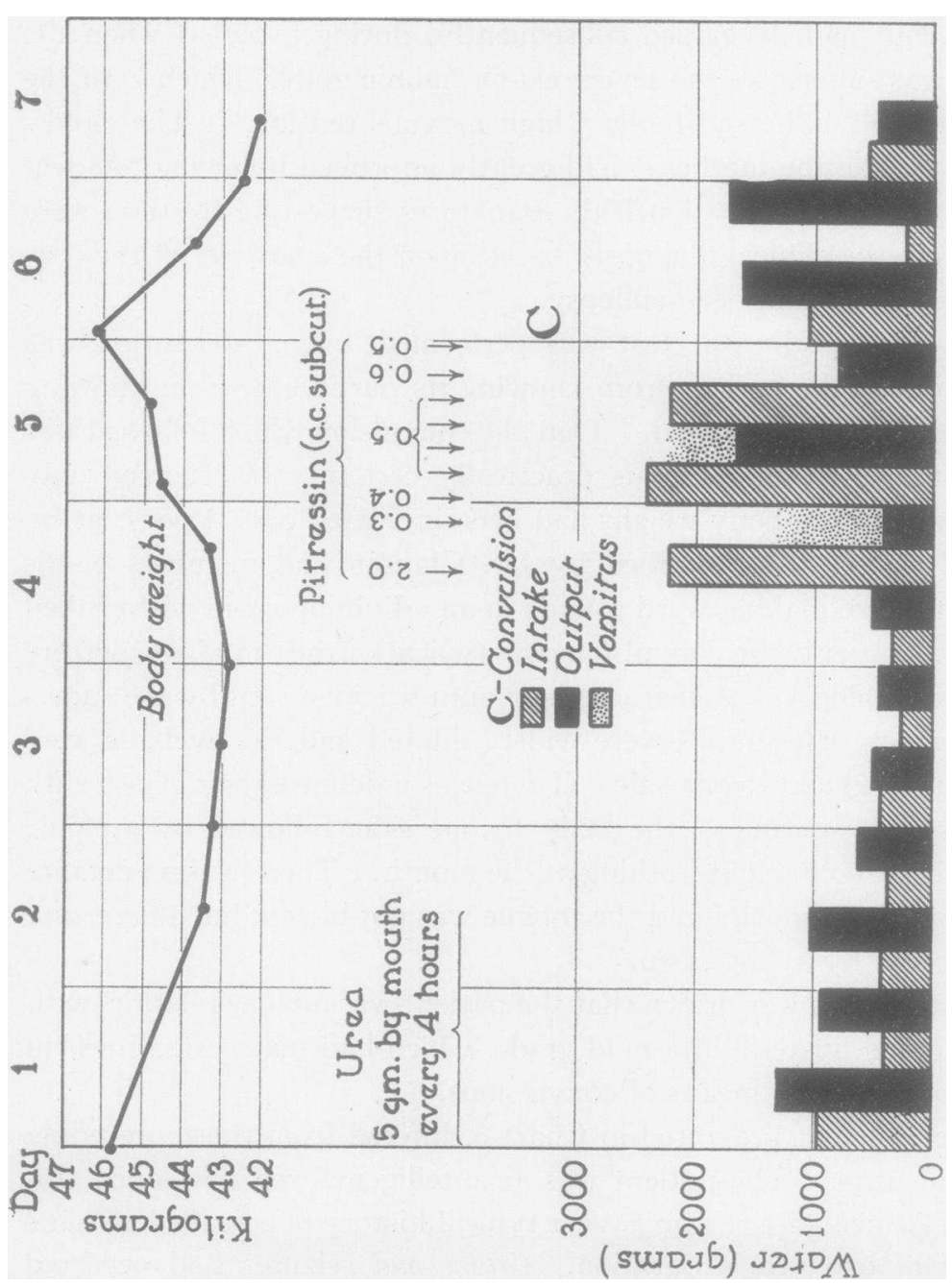


Since the history was so clearly one of epilepsy, it was decided to repeat the study under conditions in which the complete water balance of the body could be accurately determined. A preliminary period of dehydration was included because it had been observed repeatedly in severe epileptics that seizures were likely to be more frequent and more severe on resuming a high water intake following a period of freedom and low intake. It was considered that this might prove to be an additional refinement in the test, to bring out the latent convulsive tendency in the epileptic subject. A considerable degree of dehydration was produced by administration of urea over a period of 36 hours and limitation of the total water intake over a period of three and one-half days. Sufficient water was then given over a period of a few fours to completely satisfy the patient's desire for it (over $1000 \mathrm{cc}$.), after which the routine administration of the antidiuretic extract of the pituitary gland and water was begun.

In order to avoid unpleasant reactions, and to prevent complications such as vomiting, the plan previously evolved was to begin with a small dose of pitressin and gradually increase this until the optimum dosage was reached. Inadvertently, the substitute nurse in charge injected ten times the intended amount of pitressin for the first dose. The patient's reaction to this overdosage was extremely intense. There were marked and persistent pallor of the skin and mucous membrane, with feeling of faintness and collapse, weakness and irregularity of the pulse, abdominal discomfort, dizziness, headache and persistent vomiting but no convulsion nor loss of consciousness. Incidentally, this episode, while distressing in one respect, proved to be of great value in that it demonstrated beyond reasonable doubt that the convulsions induced in the epileptic subjects studied are not associated primarily with the vasopressor action of the extract, but with its antidiuretic or hydrating effect.

After the pronounced symptoms of pitressin overdosage had subsided, the test was continued according to the original plan. A typical grand mal seizure occurred about 36 hours later, after nearly three liters of water had again been stored in the body. During the 24 hours preceding the convulsion, no vomiting, no headache and no striking vasopressor effect were observed. Spinal fluid pressure taken shortly after the convulsion was $125 \mathrm{~mm}$. of water. 
The marked loss in body weight after the termination of the test is of special interest. It was obviously due to a massive loss of water, largely by way of the kidneys. It is somewhat surprising that 30 hours after the convulsion the weight had fallen below the minimum for the dehydration period. Except for the period of about 20 hours when there was vomiting from overdosage of pitressin, the diet, containing 1700 Calories, was apparently well taken. This effect on the body weight, which is observed in the controls as well as in the epileptic subjects on the withdrawal of the antidiuretic agent, is similar to that of simple water diuresis, but is more marked. Whether or not this is due solely to previous loss of minerals, so that the storage depots are temporarily unable to retain their usual amount of water, or in part to other factors, is uncertain.

The purpose of the following two experiments, which were conducted in the metabolism ward under rigidly controlled conditions, was to throw some light, if possible, upon the modus operandi of the water and pituitary extract in provoking seizures in epileptic subjects. It is obvious that the addition of a large volume of distilled water to the extracellular body fluids must result in dilution of these solutions bathing the cells of the body. Under ordinary conditions, the drinking of similar amounts of water results in but little dilution, because the extra water is excreted very promptly. To the extent that minerals are carried from the body with it, there will be loss of extracellular body water also to maintain the normal concentrations.

When, however, the increased water intake is accompanied by administration at frequent intervals of an efficient antidiuretic agent, the normal mechanism for adjustment cannot operate successfully and dilution of the fluid about the cells is inevitable. If this condition persists for a sufficiently long period of time, it is practically certain that the cells will take up extra water because of the diminished osmotic pressure of the fluids surrounding them. It may be presumed that this dilution of the cell contents with resulting disturbances in the ionic equilibria results in the increased irritability of nerve tissue eventuating in the convulsion. It was thought desirable, therefore, to study the problem in a way such that the importance of the dilution factor might be more accurately appraised.

In the limited time available for this study, it was planned to keep two mildly epileptic children, who were known with certainty from 
previous observation to have grand mal attacks at relatively infrequent intervals, on basic diets extremely low in $\mathrm{NaCl}$ and on uniform water intake at a rate between 3 and 5 grams per kilogram of body weight per hour. After preliminary periods of 36 hours, the antidiuretic principle was to be given at 3-hour intervals until seizures were produced. After an interval of 24-hours, which should be allowed for recovery from the effects of this procedure, $\mathrm{NaCl}$ in sufficient amount to make approximately a $\mathbf{0 . 6}$ per cent solution of the fluid estimated to be retained, was to be given over a period of 24 hours. This was then to be continued and at the same time the antidiuretic agent was to be administered as before until a seizure should occur, or until other indications for its discontinuance should appear, after which the salt would be continued for an additional 24 hours. The remainder of the plan was to repeat the first part of the experiment 24 to 36 hours after discontinuance of the $\mathrm{NaCl}$, as an added check. The diets and water intake remained the same throughout the entire period.

As shown in Chart 6, the experiment was carried out essentially as planned. The important feature of the results obtained was that a much longer time and a much greater gain in weight were required for the induction of a seizure when $\mathrm{NaCl}$ was given than when it was not given. The convulsion, which occurred in the foreperiod, followed the third dose of pitressin; that in the sodium chloride period came approximately three hours after the 12 th dose, and that in the last period after the 6th dose. Before the seizure of the sodium chloride period occurred, the body weight reached a peak more than one kilogram above that of the low-mineral-diet period.

In the next experiment (Chart 7) there was a slight deviation from the original plan in that no pitressin was administered during the foreperiod. In this instance, during the preliminary period of increased water intake, instead of the usual loss of body weight due to water diuresis, there was a net gain of 2 per cent due to water retention and at the end of 12 hours the patient had a severe convulsion. The usual water diuresis then followed during the next 24 hours. The increase in weight during the succeeding 24 hours, due alone to the addition of $\mathrm{NaCl}$, while materially greater than the first gain, was unaccompanied by a seizure. Nor was there a seizure when the body weight was made to increase by more than 5 per cent by the simultaneous administration 


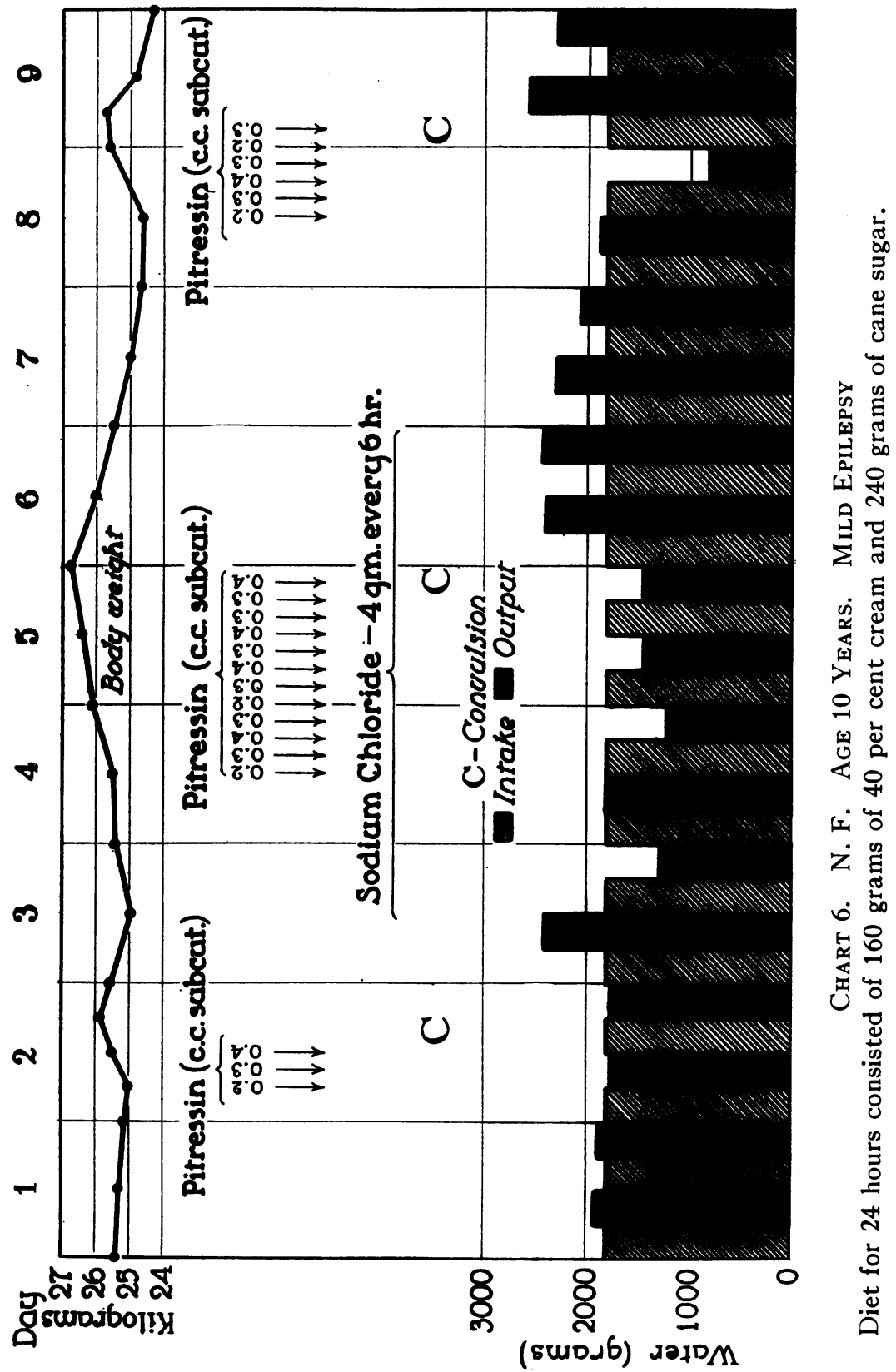




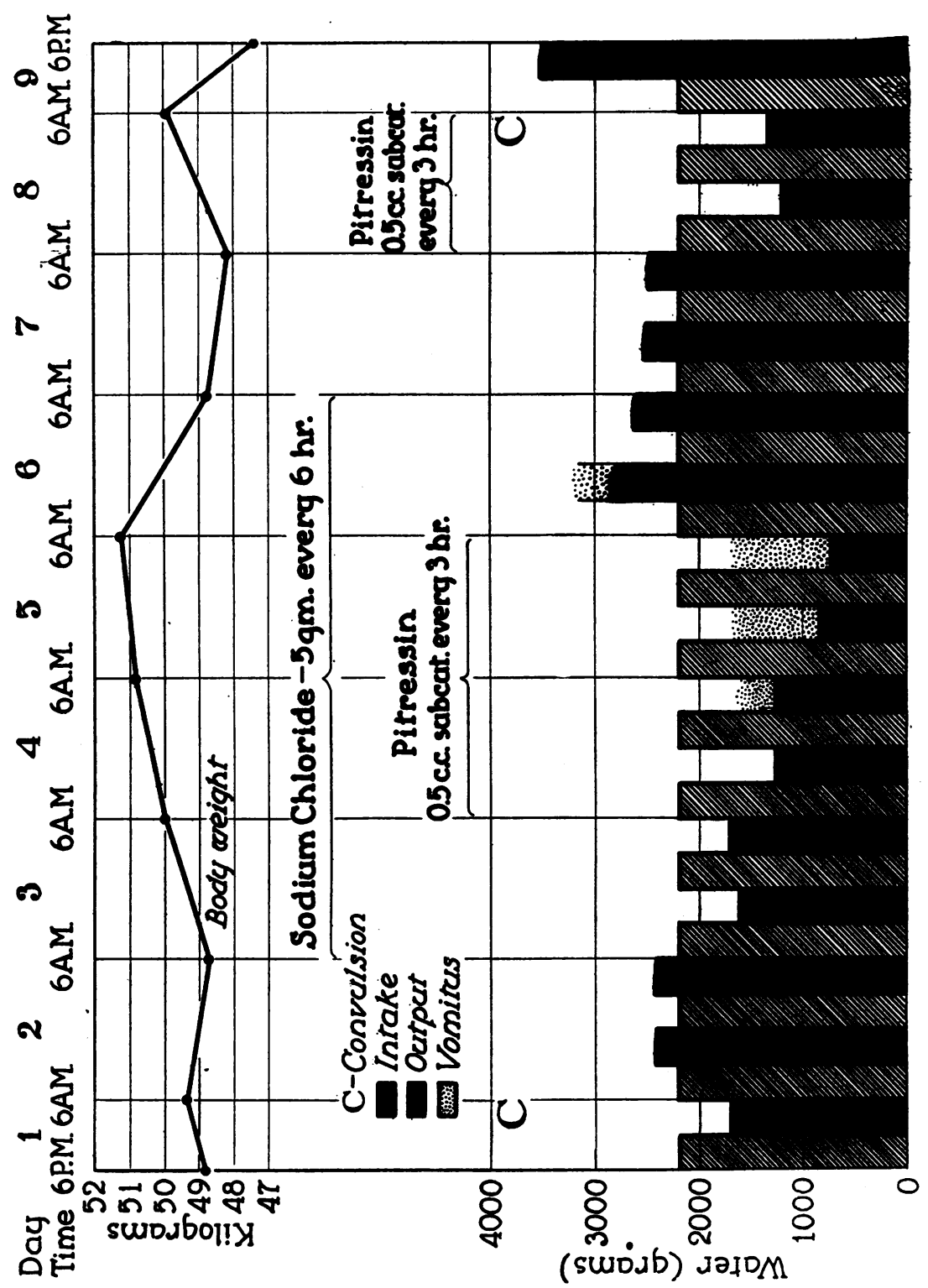

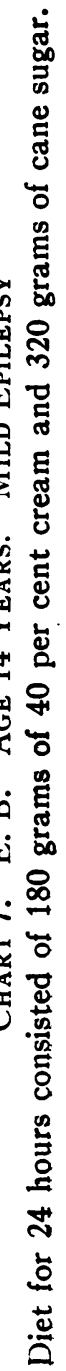


of hypotonic salt solution and pituitary extract, although headache, vomiting and circulatory symptoms were so severe that the experiment had to be discontinued on the fourth day. Evidently, the prevention of dilution of the extracellular body fluids in this experiment interfered with the induction of a seizure. The third phase of the experiment was carried out 24 hours after withdrawal of the $\mathrm{NaCl}$. In spite of the fact that not all of the $\mathrm{NaCl}$ given had yet been excreted, as shown by subsequent measurements, repetition of the antidiuresis test, without addition of $\mathrm{NaCl}$, resulted in a typical grand mal attack within 20 hours. It is planned to compare the effects of other ions with those of $\mathrm{Na}$ and $\mathrm{Cl}$ in experiments similar to these. In a study on the relative effectiveness of the various ions in inhibiting the swelling of brain tissue, placed in distilled water, Haldi and his coworkers (9) found a considerable difference between the different ions. The bivalent were more efficient than the monovalent ions in preventing swelling.

Since the experiments described here were done, we have seen the antidiuresis test carried out on more than forty mildly epileptic children, in all but one of whom seizures have resulted as in these cases. None of the eighteen definitely non-epileptic subjects observed have reacted in this way, although in the majority of them the duration of the test has been longer, the weight increase greater, and the other symptoms of overdosage more marked. In but one case so far have we seen genuine petit mal seizures definitely induced by this procedure. ${ }^{3}$ In this particular patient the minor seizures were provoked on three successive occasions. On the first of these, when larger doses of pitressin were given, she had one grand mal attack, as well as several petit mal seizures. We have watched the effect of the test on but one patient who had frequent spontaneous petit mal attacks without ever having had grand mal. In this instance the special nurse reported an increase in the frequency and severity of the petit mal seizures. This particular problem undoubtedly deserves further investigation, because the mechanism of petit mal seems to differ in some respects from that of grand mal as seen in the mild cases described in this paper.

One of the other cases, which was of special interest to us, was that of a man 23 years of age with typical hysterical attacks. Our positive

${ }^{3}$ To be reported in connection with mineral and water metabolism studies being made by McQuarrie, Ziegler and Engel. 
water-balance test was performed on him at the request of the staff in Neuropsychiatry during one of his "free" periods. No type of seizure resulted from prolonged continuation of the procedure, although he had headache, vomiting, vasomotor symptoms and a gain in body weight of more than 5 per cent. Some days later, after the effects of the test had entirely disappeared, he was made to have one of his ordinary hysterial "convulsive attacks" by a clever arrangement of circumstances, discussion of which is beyond the scope of the present paper. Details of this case will be reported independently by Dr. C. B. Horton.

\section{DISCUSSION}

It is evident from the foregoing results that typical grand mal seizures can be induced in children with epilepsy, even in the early stages and during the free intervals between spontaneous attacks, by materially increasing the water intake and administering at the same time a sufficient amount of antidiuretic pituitary extract to prevent water diuresis. A low mineral intake during the test apparently favors this type of response, whereas preventing dilution of the body fluids tends to interfere with the induction of seizures. In essentially normal children, presenting simple problems of social maladjustment or ordinary "nervousness," and in other non-epileptic subjects with hysteria or with typical "shaking" or "fainting spells," the procedure when applied in the way described here does not cause convulsive reactions of any kind. Apparently very little, if any, harm to the patient results from it. We believe, therefore, that it may be employed as an aid in differential diagnosis in early or obscure cases, in which other more simple methods of provoking the characteristic seizure fail.

In addition to their practical implications, the foregoing experimental data appear to us to contribute significant information on what may be termed the "physicochemical pathology" of "genuine" epilepsy. Before our tentative interpretation in this connection is presented, however, other possible explanations of the results obtained will be briefly discussed.

Because of the tendency for convulsions to follow interference with blood supply to the brain (10) and because anoxemia has been shown by Lennox and Cobb (4) to favor the occurrence of seizures in epilepsy, it was natural at first to think that the seizures might be due to the vaso- 
pressor effect of the pituitary extract. However, three objections to this interpretation have appeared. The first of these is that there has been no regular time relationship between the occurrence of seizures and the transient vasopressor effect of the extract, which follows within a few minutes after the injection. The next is that seizures tend to occur only after a positive water balance of a considerable magnitude has been established. In the third place, while the vasopressor reaction may well be a contributing factor in some instances, the experiment presented on Chart 5 would tend to convince the most enthusiastic proponent of the vascular-spasm theory that it is not of primary importance under the conditions of this test. Were the theory applicable under these circumstances, it would seem certain that the patient should have had a seizure, or more likely many seizures, when she was inadvertently given ten times the intended dose with the production of a vasopressor reaction of almost maximal intensity.

The next possibility which presents itself as the direct cause of the convulsions is increased intracranial pressure, which has been thought by some writers to be an important factor in epilepsy. This was at first considered by Rowntree and his coworkers (11) (12) to be the major factor in the causation of convulsions in experimental "water intoxication," a reaction similar in certain respects to that of our experiments. Generalized convulsions, which were said in their earlier papers to be epileptiform in type, were produced in normal experimental animals by these observers, when water was administered at the enormous rate of 100 cc. per kilogram of body weight per hour or when half of this amount of water was given in conjunction with sufficient pituitrin to prevent diuresis. In a later paper Rowntree (13) described the convulsions as resembling those of strychnine poisoning and expressed the belief that a disturbance in the balance of the electrolytes is of paramount importance in their causation.

The chief objection to the theory of increased intracranial pressure in connection with our experiments is that the spinal fluid pressure readings, taken regularly on the patients soon after their seizures and in a number of instances just before, have varied between 80 and 130 millimeters of water, which is well within the normal range of variation. In two instances convulsions occurred while the spinal fluid pressure was being measured. Although the reading taken at the height of the 
convulsion in each case was above $200 \mathrm{~mm}$. of water, the values recorded immediately before and a few minutes after it were well within normal limits. No difference has been found between the pressures of the epileptic patients and those of the non-epileptic subjects, on whom determinations have been made under the same conditions. The rate of water administration to our patients was but one twentieth to one thirtieth that used by Rowntree to produce convulsions in his normal animals. Unless an unexpectedly large fraction of the water retained in the body were stored within the skull, it is most unlikely that sufficient increase in general pressure to cause seizures should develop from the comparatively small amount of water given. We have been unable to influence the occurrence of convulsions in our subjects by increasing the intracranial pressure by jugular compression. Even in other convulsive conditions, in which increased intracranial pressure is conceded to be a contributing causal factor, the exact nature of the pressure effect and its relation to the convulsion are not known. It is conceivable that the injury to the brain cells from direct pressure and from interference with blood supply may be sufficient to alter the permeability of their membranes to water and electrolytes.

In Rowntree's normal animals with water intoxication there was observed no tendency for water to localize in the subarachnoid spaces in spite of the enormous quantity administered (13). In the few epileptic cases in which attempts have been made by Thompson to remove the fluid from the subarachnoid system quantitatively and replace it by air, first some weeks before, then during and again some weeks after the antidiuresis test, the results have indicated that the total volume of fluid tends to be slightly diminished rather than increased during the time when the water retention in the body is at its maximum. ${ }^{4}$ Barbour and his coworkers (14) found that the water content of the brain tissue itself is increased in dogs under conditions similar to those of our experiments. It appears probable to us, therefore, that the volume of cerebrospinal fluid may even decrease as the volume of the brain tissue increases, in keeping with the space-compensation theory of Dandy (15).

We do not regard ordinary intercellular brain edema, which is referred to by some authors, as being of great importance in the causation of epileptic seizures. However, entrance of water or hypotonic $\mathrm{NaCl}$

1 Personal communication. 
solution into the cells in excessive quantities with resulting dilution of the cell contents and alteration of the normal relationships of both colloids and electrolytes would be considered of very great significance. Some indirect evidence that such a translocation of water may precede the occurrence of a seizure provoked by sustained pituitary antidiuresis has recently been obtained from a combined study of the water and mineral balances in a severely epileptic patient (16). The view was expressed in an earlier paper (2) that the beneficial effect of the dehydrating regimen used in the treatment of epilepsy might depend in large part upon its preventing overhydration of the brain cells, rather than upon its decreasing the quantity of fluid in the subarachnoid spaces, as maintained by Fay (17). The results from the present study, as well as certain other experimental data now available, tend to support that position.

Under the conditions of the experiments reported here, in which the subject on a low mineral diet is forced by sustained antidiuresis to retain a volume of water greater in some instances than that of the total plasma volume, a significant decrease in the total osmolar concentration of the electrolytes in the extracellular fluids of the body is found to take place. Due to the resulting alteration in the osmotic pressure of this fluid, there is undoubtedly a strong tendency for the fixed cells of the brain and of other organs to take up water and to lose some of their diffusible elements. The fact, that convulsions are inducible in the epileptic but not in the non-epileptic subject under these particular conditions, suggests that the barrier, normally preventing free passage of water and various solutes into and out of the brain cells, functions inefficiently in the former. This interpretation is consistent with a working hypothesis which has recently been derived from separate studies on the blood lecithin and cholesterol (18) and on the mineral and water exchanges (16) in severely epileptic patients. The central concept in this hypothesis is that an innate deficiency in the mechanism for controlling semi-permeability of the brain cell membranes characterizes the physicochemical pathology of "essential" epilepsy.

SUMMARY AND CONCLUSION

1. Experimental and clinical data are presented to show the effects of sustained pituitary antidiuresis and water drinking on mildly epileptic as contrasted with non-epileptic children. 
2. It is shown that typical grand mal seizures can be induced within 12 to 48 hours in the epileptic, but not in the non-epileptic subject, by giving water at the rate of from 2 to $5 \mathrm{cc}$. per kilogram of body weight per hour while maintaining effective pituitary antidiuresis.

3. This difference in response between epileptic and non-epileptic patients may be helpful in establishing the diagnosis early in an obscure case.

4. Under the conditions of the experiments described here, dilution of the extracellular body fluids appears to be an essential factor in the induction of seizures since administration of an amount of $\mathrm{NaCl}$ just sufficient to prevent this tends to interfere with their occurrence.

5. The results presented lend strong support to the view that the mechanism for controlling semipermeability of the brain cell membranes is inherently defective in the epileptic patient.

\section{BIBLIOGRAPHY}

1. McQuarrie, Irvine, Am. J. Dis. Child., 1929, xxxviii, 451. Epilepsy in Children. The Relationship of Water Balance to the Occurrence of Seizures.

2. McQuarrie, Irvine, Manchester, R. C., and Husted, Clara, Presented before the Association for Research in Nervous and Mental Diseases, New York City, December, 1929. (In Press.) The Effect of Induced Changes in State of Hydration upon the Occurrence of Seizures in Epileptic Children.

3. Foerster, O., Deutsches Ztschr. f. Nervenh., 1924, lxxxiii, 347. Hyperventilationsepilepsie.

4. Lennox, W. G., and Cobb, Stanley, Medicine, 1928, vii, 105. Epilepsy from the Standpoint of Physiology and Treatment.

5. McQuarrie, Irvine, and Keith, H. M., Am. J. Dis. Child., 1929, xxxvii, 261. Experimental Study of the Acid-Base Equilibrium in Children with Idiopathic Epilepsy.

6. Dandy, W. E., Ann. Surg., 1919, lxx, 397. Roentgenography of the Brain after the Injection of Air into the Spinal Canal.

7. Pancoast, H. K., and Fay, T., Am. J. Roentgenol., 1929, xxi, 421. Encephalography; Roentgenological and Clinical Considerations for Its Use.

8. Pendergrass, E. P., S. Clin. North America, 1930, x, 1461. The Value of and Indications for Encephalography and Ventriculography, with Discussion of the Technic.

9. Haldi, J. A., Rauth, J. W., Larkin, J., and Wright, P., Am. J. Physiol., 1927, 1xxx, 631. A Study of Anion and Cation Effects on Water Absorption by Brain Tissue. 
10. Stewart, G. N., Guthrie, C. C., Burns, R. L., and Pike, F. H., J. Exp. Med., 1906, viii, 289. The Resuscitation of the Central Nervous System of Mammals.

11. Weir, J. F., Larson, E. E., and Rowntree, L. G., Arch. Int. Med., 1922, xxix, 306. Studies in Diabetes Insipidus, Water Balance and Water Intoxication.

12. Rowntree, L. G., Physiol. Rev., 1922, ii, 116. The Water Balance of the Body.

13. Rowntree, L. G., J. Pharm. and Exper. Therap., 1926, xxix, 135. The Effects on Mammals of the Administration of Excessive Quantities of Water.

14. Ellerbrook, G. E., Dunham, E. S., and Barbour, H. G., J. Pharmacol. and Exper. Therap., 1930, xxxix, 256. Effects of Diuretic Doses of Pitressin upon the Distribution of Water in the Brain and Other Tissues.

15. Dandy, W. E., Bull. Johns Hopkins Hosp., 1923, xxxiv, 245. The Space Compensating Function of the Cerebrospinal Fluid. Its Connection with Cerebral Lesions in Epilepsy.

16. McQuarrie, Irvine, Husted, Clara, and Manchester, R. C. (in press), Am. J. Dis. Child., 1931. Studies on the Water and Mineral Metabolism in Epilepsy.

17. Fay, T., Am. J. Psychiat., 1929, viii, 783. Some Factors in the "Mechanical Theory of Epilepsy" with Especial Reference to the Influence of Fluid, and Its Control, in the Treatment of Certain Cases.

18. McQuarrie, I., Bloor, W. R., Patterson, H. C., and Husted, C., Am. J. Dis. Child., 1931, xlii, 720. The Possible Significance of Blood Lipid Changes in Epilepsy. 